\title{
Cucumeris Mite (Suggested Common Name) Neoseiulus cucumeris (Oudemans) (Arachnida: Mesostigmata: Phytoseiidae) ${ }^{1}$
}

\author{
Garima Kakkar, Vivek Kumar, Cindy McKenzie, and Lance Osborne ${ }^{2}$
}

\section{Introduction}

Neoseiulus cucumeris (Oudemans), first described by Oudemans in 1930, is a generalist foliar predator known worldwide for its biocontrol potential against a spectrum of pests (whiteflies, thrips, mites, aphids, and psyllids) of horticultural importance. Its ability to survive on plant pollen in the absence of prey and commercialization make this mite one of the most easily adaptable and readily available natural enemies for greenhouse, nursery, or interiorscape production systems. Because of its broad host range and ability to survive on plant pollen it has been categorized as a type III predator (McMurtry and Croft 1997).

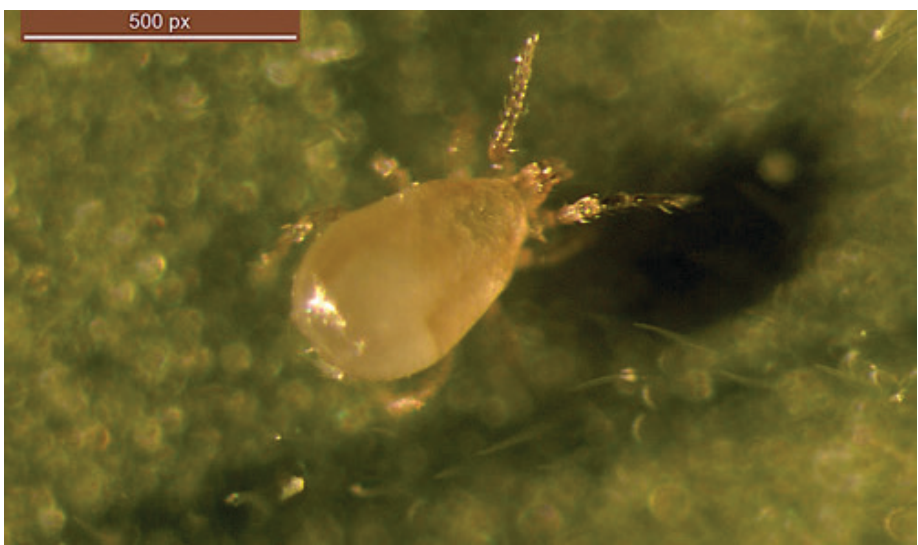

Figure 1. Neoseiulus cucumeris (Oudemans) adult. Credits: Garima Kakkar, UF/IFAS

\section{Synonymy}

The first description of this predatory mite was based on specimens found in muskmelon infested with Tetranychus spider mites, collected in France (Beard 1999). In the following years, it was described multiple times and confused with many other mite species around the world due to limited character states available for species separation and lack of sophisticated tools. Due to multiple descriptions from various parts of the world, it was named differently over time until 1989, when McMurtry and Bounfour described it as Neoseiulus cucumeris and raised Neoseiulus to the genus level. It is now the most widely accepted name for this species. Synonyms of Neoseiulus cucumeris are:

Typhlodromus cucumeris Oudemans

Typhlodromus thripsi MacGill

Amblyseius cucumeris (Oudemans) Athias-Henriot

Amblyseius (Typhlodromopsis) cucumeris (Oudemans)

Typhlodromus (Amblyseius) cucumeris (Oudemans)

Amblyseius (Amblyseius) cucumeris Wainstein

1. This document is EENY661, one of a series of the Department of Entomology and Nematology, UF/IFAS Extension. Original publication date July 2016. Visit the EDIS website at http://edis.ifas.ufl.edu. This document is also available on the Featured Creatures website at http://entnemdept.ifas.ufl.edu/ creatures/.

2. Garima Kakkar, Extension agent II, UF/IFAS Extension St. Lucie County; Vivek Kumar, post doctoral associate, Department of Entomology and Nematology, UF/IFAS Mid-Florida Research and Education Center; Cindy McKenzie, United States Horticulture Research laboratory, ARS-USDA; and Lance S. Osborne, professor, Department of Entomology and Nematology, UF/IFAS Mid-Florida REC; UF/IFAS Extension, Gainesville, FL 32611. 
Neoseiulus coprophilus (Karg)

Neoseiulus bellinus (Womersley)

Neoseiulus thripsi (MacGill)

Amblyseius (Neoseiulus) cucumeris (Oudemans)

\section{Distribution}

Neoseiulus cucumeris has a worldwide distribution because of its natural occurrence and commercial use in various parts of the world. It has been reported from Algeria, Armenia, Australia (Australian Capital Territory, Tasmania), Austria, Azerbaijan, Belarus, Belgium, Canada (British Columbia, Nova Scotia, Ontario, Quebec), Canary Islands, Caucasus Region, Cyprus, Egypt, England, France, Georgia, Germany, Greece, Hungary, India (Punjab), Iran, Israel, Italy, Latvia, Mexico, Moldova, Morocco, the Netherlands, New Zealand, Poland, Portugal, Russia (Moscow), Saudi Arabia, Slovakia, Slovenia, Spain, Switzerland, Tunisia, Turkey, Ukraine, US (Alabama, California, Florida, New Hampshire, Utah, Virginia, Washington, West Virginia, Wisconsin) and the West Bank (EPPO 2016, Neoseiulus cucumeris distribution record, University of Sao Paulo).

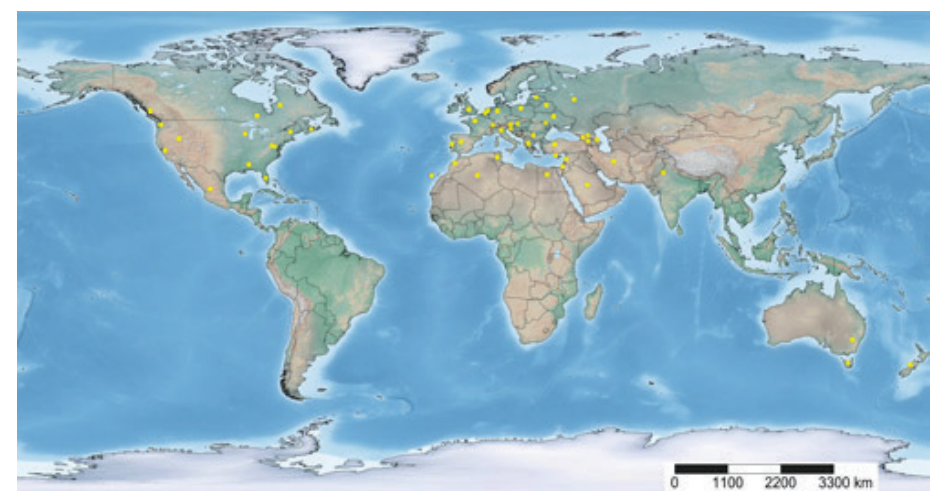

Figure 2. Distribution map of Neoseiulus cucumeris (Oudemans). Credits: Vivek Kumar, UF/IFAS

\section{Description and Biology}

Neoseiulus cucumeris is soft-bodied and translucent pale brown to sometimes tan-colored depending on the food consumed. The adult mite is pear shaped and may range between $0.5-1.0 \mathrm{~mm}$ in length. Due to its small size, it is not easily visible with the naked eye and can be best seen with a hand lens of at least $10 \times$ magnification or under a stereoscope. On plants in the field and greenhouse, Neoseiulus cucumeris is not easily distinguished from other predatory mites commonly encountered in horticultural production such as Amblyseius swirskii Athias-Henriot and Neoseiulus californicus McGregor. In the past Neoseiulus cucumeris was described as a complex of cryptic species (taxon exhibiting morphologically indistinguishable characteristics and reproductively distinct species) and variations in their ecology, distribution, habitat preference, dispersal and feeding behaviors have been reported (Beard 1999).

Neoseiulus cucumeris develop through one larval stage and two nymphal stages (protonymph and deutonymph) before becoming adults. The life cycle from egg to adult may be completed in nine to 12 days at $25^{\circ} \mathrm{C}$ and adults may live up to 28-35 days. Eggs of Neoseiulus cucumeris are oval, translucent white and $\sim 0.14 \mathrm{~mm}$ in diameter. An adult female produces an average of 35 eggs during her lifetime. Eggs are laid on the leaf surface, on domatia or on hairs along the midrib on the underside of leaves, and occasionally on petiole hairs. The non-feeding larvae emerge from eggs in about three days and molt into protonymphs two days later. The two nymphal stages last for seven to 10 days before developing into adults. However, these biological parameters change depending on available food sources. In their studies, Van Rijn and Tanigoshi (1999) and Sarwar (2016) reported that although this predator could survive and reproduce solely on pollen diets (variable results on different pollen), the survival, longevity and fecundity were higher when prey was included in the diet. Similar observations on the effect of pollen versus prey diets on the longevity or oviposition of other phytoseiid mites including Amblyseius deleoni (Muma and Denmark) (Rasmy et al. 2000) and Amblyseius swirskii (Kumar et al. 2014) have been previously recorded.

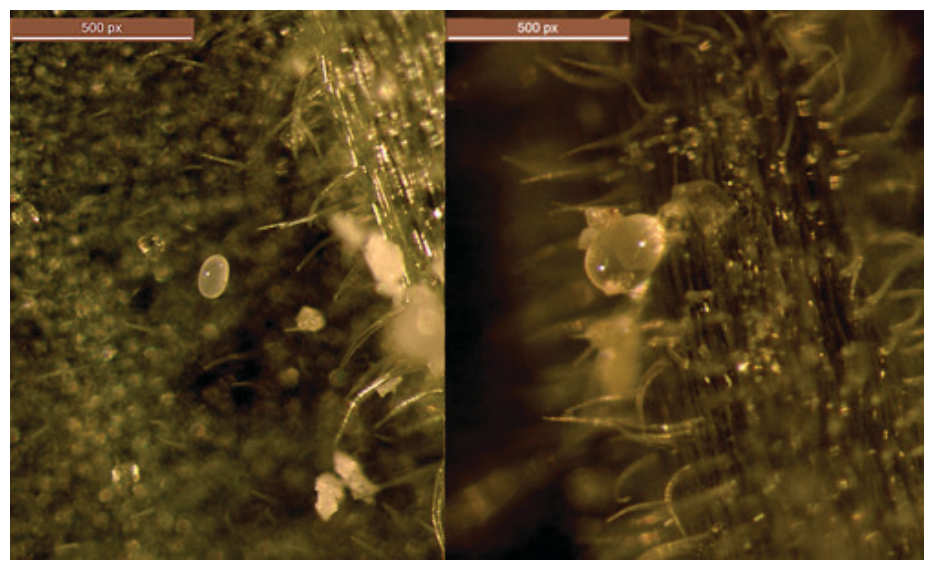

Figure 3. Eggs of Neoseiulus cucumeris (Oudemans). Credits: Garima Kakkar, UF/IFAS

\section{Host Range}

Neoseiulus cucumeris is an aggressive predator of several soft-bodied pests, generally seen on the lower leaf surface or inside flowers. They are known to feed on the immature stages of a variety of pests (McMurtry and Croft 1997) including important thrips species; western flower thrips 
(Van Houten et al. 1995), onion thrips (Broadsgaard and Hansen 1992), melon thrips, common blossom thrips (Kakkar et al. 2016), and chilli thrips (Arthurs et al. 2009); Asian citrus psyllid (Fang et al. 2013); whitefly (silverleaf) (Zhang et al. 2011), and plant damaging mites; broad mite (Weintraub et al. 2003), cyclamen mite (Croft et al. 1998, Easterbrook et al. 2001), spider mite (Easterbrook et al. 2001), and tomato russet mite (Brodeur et al. 1997).

Commercially available Neoseiulus cucumeris are capable of suppressing a wide range of pests but variations in their behavior in different regions (allopatric populations) can be expected. Variation in their predation potential against a target pest can also differ in single versus multiple pest situations. Because these mites prefer to feed on easily-available prey on a host plant, lower control of flower-inhabiting thrips can be expected in the case of heavy infestation of a foliage pest such as whitefly, thrips, or broad mite. In a recent study, Kakkar et al. (2016) found Neoseiulus cucumeris significantly suppressed melon thrips on cucumber leaves, but failed to control common blossom thrips inhabiting the cucumber flowers. Thus, in the case of multiple pests inhabiting different plant parts, a higher rate or multiple predator releases may be required to achieve the desired level of control.

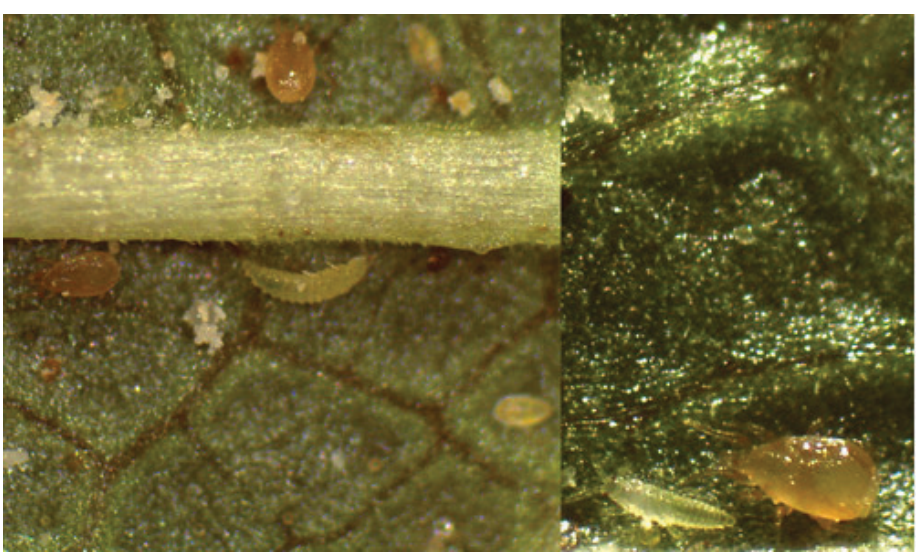

Figure 4. Neoseiulus cucumeris adult chasing orchid thrips larva on a Salvia nemorosa L. leaf.

Credits: Vivek Kumar, UF/IFAS

\section{Economic Importance}

Neoseiulus cucumeris was the first phytoseiid mite found to feed on thrips (Macgill 1939), but until 1980, its use in thrips management was little explored (Ramakers 1980, Gerson and Weintraub 2007). However, in the past three decades, due to growing concerns over risks (resistance, environmental, health) associated with chemical control, the use of alternate pest management strategies has received considerable attention. In that context, the use of generalist predators that can perform as a broad spectrum insecticide has been greatly encouraged. Currently in the
US, Neoseiulus cucumeris is commercially available by the member companies of the Association of Natural Biocontrol Producers (ANBP) including Tip Top Bio-Control, Bio Control, S.A., Koppert, Rincon-Vitova, Distribuciones IMEX S.A. de C.V., Anatis Bioprotection, Entomology Solutions, Natural Insect Control, Applied Bio-nomics, Hydro-Gardens, Beneficial Insectary, Sound Horticulture, Crop Defenders, Buglogical Control Systems, M\&R Durango, IPM Laboratories, Biobest, EcoSolutions, Natural Enemies Bio. Pest Mgmt., Everwood Farm, ARBICO Organics, Evergreen Growers Supply, Green Methods, Syngenta Bioline, and Orcon (LeBeck and Leppla 2010).

In recent years, various formulations (delivery systems) of Neoseiulus cucumeris have been developed to improve their survival and dispersal in commercial crop production systems. Buckets (100,000 mites) or bottled (50,000 mites) containers are available for direct release in field, greenhouse, and nursery operations. Both systems consist of predatory mites and bran mites (Tyrophagus putrescentiae Schrank, a temporary food source of the predatory mite) mixed with bran or vermiculite. Mite application rates can vary depending upon the crop, climatic conditions, pest species and density, resulting in the recommended application rate to range between $50-100$ mites per $\mathrm{m}^{2}$. A slow release delivery system (controlled release method) is also available, where mites along with the dispersal medium and temporary food are contained in sachets (1000 mites/ sachet) that can be hung on the host plants. Tiny pores within the sachets allow gradual movement of the mite nymphs onto the host plants in subsequent weeks following their application.

Although, the predatory mites feed aggressively on several pest species, time spent in prey searching, reproduction, and their dispersion to cover the affected area can slow the pest management. Due to this shortcoming, Neoseiulus cucumeris is generally used as a preventive control tool and can provide efficient control of a pest in its incipient stage of infestation. Neoseiulus cucumeris can be integrated with some of the chemical insecticides (buprofezin, pymetrozine, flonicamid, fenoxycarb) for the sustainable management of various pests. However, chemistries like abamectin, acephate, bifenthrin, chlorenapyr, cyfluthrin, esfenvalerate, fipronil, imidacloprid, spinosad, and thiamethoxam can be toxic to Neoseiulus cucumeris life stages. In a production system, strategic rotation of Neoseiulus cucumeris with benign insecticides can reduce the overall use of harsh chemistries and delay the insecticide resistance selection in a pest population. 


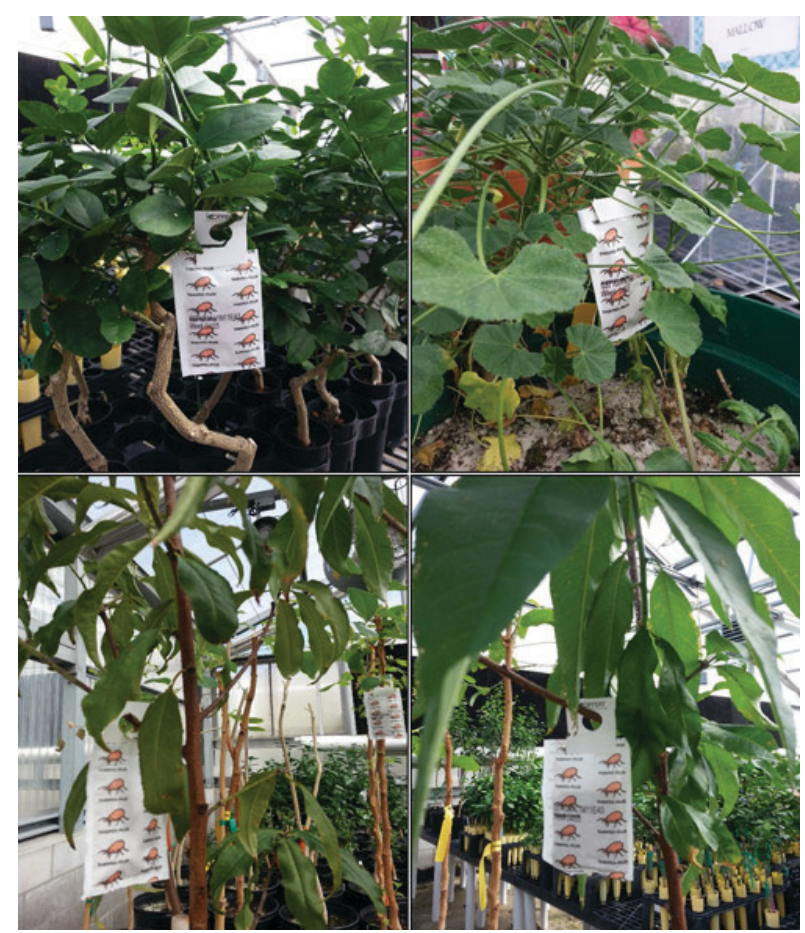

Figure 5. Slow-release sachet of Neoseiulus cucumeris hung on different hosts in the greenhouse.

Credits: Vivek Kumar, UF/IFAS

\section{Selected References}

Arthurs S, McKenzie CL, Chen J, Doğramaci M, Brennan M, Houben K, Osborne L. 2009. "Evaluation of Neoseiulus cucumeris and Amblyseius swirskii (Acari: Phytoseiidae) as biological control agents of chilli thrips, (Thysanoptera: Thripidae) on pepper." Biological Control 49: 91-96.

Beard JJ. 1999. “Taxonomy and biological control: Neoseiulus cucumeris (Acari: Phytoseiidae), a case study". Australian Journal of Entomology 38: 51-59.

Brodeur J, Bouchard A, Turcotte G. 1997. "Potential of four species of predatory mites as biological control agents of the tomato russet mite, Aculops lycopersici (Massee) (Eriophyidae)". Canadian Entomologist 129: 1-6.

Brodsgaard HF, Hansen LS. 1992. "Effect of Amblyseius cucumeris and Amblyseius barkeri as biological control agents of Thrips tabaci on glasshouse cucumbers". Biocontrol Science and Technology 2: 215-223.

Croft BA, Pratt PD, Koskela G and Kaufman D. 1998. "Predation, reproduction, and impact of phytoseiid mites (Acari: Phytoseiidae) on cyclamen mite (Acari: Tarsonemidae) on strawberry." Journal of Economic Entomology 91: 1307-1314.

Easterbrook MA, Fitzgerald JD, Solomon MG. 2001. "Biological control of strawberry tarsonemid mite Phytonemus pallidus and two-spotted spider mite Tetranychus urticae on strawberry in the UK using species of Neoseiulus (Amblyseius) (Acari: Phytoseiidae)". Experimental and Applied Acarology 25: 25-36.

EPPO (European and Mediterranean Plant Protection Organization). 2013. Commercially used biological control agents - Arachnida, Acarina. (27 June 2016)

Fang X, Lu H, Ouyang G, Xia Y, Guo M, Wu W. 2013. "Effectiveness of two predatory mite species (Acari: Phytoseiidae) in controlling Diaphorina citri (Hemiptera: Liviidae)." Florida Entomologist 96: 1325-1333.

Gerson U, Weintraub PG. 2007. "Mites for the control of pests in protected cultivation." Pest Management Science 63: 658-676.

Kakkar G, Kumar V, Seal DR, Liburd OE, Stansly P. 2016. "Predation by Neoseiulus cucumeris and Amblyseius swirskii on Thrips palmi and Frankliniella schultzei on cucumber." Biological Control 92: 85-91.

Kumar V, Wekesa V, Avery PB, Powell CA, McKenzie CL, Osborne LS. 2014. "Effect of pollens of various ornamental pepper cultivars on the development and reproduction of Amblyseius swirskii (Acari: Phytoseiidae)". Florida Entomologist 97: 367-373.

LeBeck LM, Leppla NC. 2010. Guidelines for Purchasing and Using Commercial Natural Enemies and Biopesticides in North America. IPM-146. Gainesville: University of Florida Institute of Food and Agricultural Sciences. (27 June 2016)

MacGill EI. 1939. "A gamasid mite (Typhlodromus thripsi n.sp.), a predator of Thrips tabaci Lind." Annals of Applied Biology 26: 309-317.

McMurtry JA, Croft BA. 1997. "Life styles of phytoseiid mites and their roles in biological control". Annual Review of Entomology 42: 291-321.

Ramakers PMJ. 1980. "Biological control of Thrips tabaci (Thysanoptera: Thripidae) with Amblyseius spp. (Acari: Phytoseiidae)". International Organization for Biological and Integrated Control/West Palaearctic Regional Section Bulletin 3: 203-208.

Rasmy AH, Zaher MA, Momen FM, Sarwar NM, Abou-Elella GM. 2000. "The effect of prey species on biology and predatory efficiency of some phytoseiid mites: 
I - Amblyseius deleoni (Muma \& Denmark)”. Egyptian

Journal of Biological Pest Control 10: 117-121.

Sarwar M. 2016. "Comparative life history characteristics of the mite predator Neoseiulus cucumeris (Oudemans) (Acari: Phytoseiidae) on mite and pollen diets". International Journal of Pest Management 62: 140-148.

Van Houten YM, Van Rijn PCJ, Tanigoshi LK, Van Stratum P, Bruin J. 1995. "Preselection of predatory mites for year-round control of western flower thrips (Frankliniella occidentalis), in greenhouse crops". Entomologia Experimentalis Applicata 74: 225-234.

Van Rijn PCJ, Tanigoshi LK. 1999. "Pollen as food for the predatory mites Iphiseius degenerans and Neoseiulus cucumeris (Acari: Phytoseiidae): Dietary range and life history". Experimental and Applied Acarology 23: 785-802.

Weintraub PG, Kleitman S, Mori R, Shapira N, Palevsky E. 2003. "Control of broad mites (Polyphagotarsonemus latus (Banks)) on organic greenhouse sweet peppers (Capsicum annuum L.) with the predatory mite, Neoseiulus cucumeris (Oudemans)". Biological Control 26: 300-309.

Zhang YX, Lin JZ, Zhang GQ, Xia C, Tang JJQ. 2011. “Research and application of Neoseiulus cucumeris (Oudemans) for control of Bemisia tabaci (Gennadius) on sweet pepper in plastic greenhouse". Fujian Journal of Agricultural Sciences 26: 91-97. 